\title{
Predicting pregnancy in women undergoing in-vitro fertilization with basal serum follicle stimulating hormone levels between 10.0 and $11.9 \mathrm{IU} / \mathrm{L}$
}

\author{
Dan Levin ${ }^{1}$, Sunny H. Jun², Michael H. Dahan ${ }^{1}$ \\ 'Department of Obstetrics and Gynecology, Division of Reproductive Endocrinology and Infertility, \\ McGill Reproductive Center, McGill University Health Center, Montreal, Quebec, Canada \\ ${ }^{2}$ Department of Obstetrics and Gynecology, Palo Alto Medical Foundation, Fremont, California, USA
}

\section{Abstract}

Objective: To evaluate the results of the in vitro fertilization (IVF) cycle outcomes in women whose borderline basal follicle stimulating hormone (FSH) levels were between 10.0 and $11.9 \mathrm{IU} / \mathrm{L}$ and to analyze the predictors of pregnancy in this population.

Material and Methods: A prospective cohort study was performed at an academic teaching hospital; participants were infertile couples in which the women were undergoing IVF treatment and had borderline basal highest FSH levels between 10.0 and 11.9 IU/L. Statistical modeling was performed to determine risk factors for pregnancy and clinical pregnancy.

Results: A clinical pregnancy rate of $26.5 \%$ per cycle and $35 \%$ per patient was found in the study population. Among all subjects and nonintracytoplasmic sperm injection (ICSI) subjects, younger age, higher gravidity, higher number of mature follicles on day of Human Chorionic gonadotrophin (hCG) triggering, higher number of oocytes retrieved, and number of embryos produced were significant discriminators between individuals who conceived and those who did not. However, only the number of embryos predicted those who had a clinical pregnancy when compared with those who did not. Higher gravidity, and basal estradiol (E2) levels, and lower maximum basal FSH levels predicted clinical pregnancy in non-ICSI patients. Among ICSI patients, the only predictor of pregnancy was a thicker endometrium. A trend towards higher pregnancy rates was noted in ICSI patients.

Conclusion: We showed that pregnancy rates per cycle and per patient in this population were not significantly different than those in patients with a basal FSH level below 10.0 IU/L. Preliminary evidence suggests that ICSI is the fertilization method of choice in these patients.

(J Turk Ger Gynecol Assoc 2015; 16: 5-10)

Keywords: FSH 10-12 IU/L, borderline ovarian reserve, IVF, ICSI, statistical modeling

Received: 25 November, 2014

Accepted: 10 January, 2015

\section{Introduction}

In assisted reproductive technologies (ART), treatment success depends on the correct assessment of ovarian reserve. Depletion in the quantity of ovarian follicles and concurrent reduction in oocyte quality have been termed as diminished ovarian reserve and are thought to be the main reasons for declining maternal reproductive performance with age $(1,2)$. Various dynamic and static tests have been proposed to predict ovarian function and reserve, such as basal serum Follicle stimulating hormone (b-FSH) levels, the sonographic assessment of the ovarian antral follicle count and ovarian volume, the clomiphene citrate challenge test, the antimullerian hormone levels, the exogenous FSH stimulation test, the gonadotropin releasing hormone $(\mathrm{GnRH})$ agonist stimulation test, and basal serum inhibin B levels among others (3-9). A commonly utilized test is the measurement of b-FSH levels in the early follicular phase (cycle days 2-5) (10). The use of b-FSH levels as a predictor of IVF success was first introduced in 1988 by Muasher et al. (11). There is still controversy regarding the role and accuracy of b-FSH levels in assessing ovarian reserve and counseling of patients on their chances of successful pregnancy $(12,13)$. However, b-FSH levels are regarded as important prognostic tests in assessing ovarian reserve and as the predictors of treatment success (1, 2, 9-11, 14-18).

Although variations in b-FSH results occured depending on the hormonal assay used for analysis, in general, b-FSH levels of less than $10 \mathrm{IU} / \mathrm{L}$ are considered to be normal $(1,14,16)$. At our university, a b-FSH level of $\geq 12$ IU/L is considered diminished ovarian reserve based on rare successful pregnancy rates. Pregnancy rates decline significantly as b-FSH levels become greater than 12-15 IU/L depending on the assay used at different institutions (15). The levels between 10 and 12 IU/L have been considered to be borderline $(1,14,16,19)$. 
Recently, some studies, albeit underpowered, have shown comparable results between patients under 40 years old with a b-FSH level of $<10 \mathrm{IU} / \mathrm{L}$ and those with a b-FSH level between 10 and $15 \mathrm{IU} / \mathrm{L}$, although these studies used an assay with a different cut-off (20).

An increasing number of women are delaying childbearing to a more advanced age due to various reasons (21-23). This trend has resulted in a larger number of women who search for fertility treatments at a more advanced age, and therefore, these women are at risk of elevated b-FSH levels. More women seeking infertility treatment have borderline levels of FSH and oncoming menopause (24) and have been associated with unexplained infertility (25). Success in patients with b-FSH levels between 10 and $12 \mathrm{IU} / \mathrm{L}$, levels not yet in the abnormal range, remain poorly investigated. Thus, the purpose of our study is to describe the predictors of IVF pregnancy in women with maximum day 3 serum FSH levels of 10-11.9 IU/L, on the basis of which they are classified as having borderline ovarian reserve.

\section{Material and Methods}

A prospective cohort study was conducted at the Stanford University Hospital in the Reproductive Endocrinology and Infertility Center for 12 months. Women aged 21-43 years with borderline ovarian reserve defined as basal FSH levels of 10-11.9 IU/L and who were undergoing in vitro fertilization (IVF) were examined. The classification of subject was based on the highest serum day 2-5 FSH level. Eight hundred and sixty-six patients underwent fresh IVF cycles during the study period. Donor/recipient and frozen embryo cycles were excluded from this study.

FSH screening was performed on cycle days 2-5 in all patients. FSH levels were usually assessed at the initial infertility evaluation and were obtained within 6 months of treatment.

The controlled ovarian hyperstimulation protocol consisted of pretreatment with oral contraceptive pills with overlapping GnRH agonist downregulation, followed by FSH/human menopausal gonadotropin (hMG), microdose flare agonist, or antagonist protocols. Oocytes were inseminated conventionally or by ICSI 3-4 hours after retrieval. Embryos were cultured in groups under mineral oil in $150-\mu \mathrm{L}$ droplets of P1 medium (Irvine Scientific, Santa Anna, CA, USA) or Quinn's Advantage Cleavage medium (Cooper Surgical, Trumbull, CT, USA) with $10 \%$ serum substitute supplement (SSS) or $10 \%$ serum protein substitute (SPS) at $37^{\circ} \mathrm{C}$ in a $5 \% \mathrm{O}_{2}, 5 \% \mathrm{CO}_{2}$, and $90 \% \mathrm{~N}_{2}$ environment for 72 hours. In the blastocyst transfer group, embryos were transferred on day 3 to blastocyst medium (Irvine Scientific) or Quinn's Advantage Blastocyst medium (Cooper Surgical) with $10 \%$ SSS or $10 \%$ SPS and cultured for 48 hours before transfer.

Three physicians performed the transfers; all used a similar technique. A Tefcat catheter (Cook IVF, Spencer, IN, USA) was used to deposit embryos $1.5-2 \mathrm{~cm}$ short of the fundus under transabdominal ultrasound guidance, with a transfer volume of 20-30 $\mu \mathrm{L}$. Clinical pregnancies (CPs) were defined by the presence of a gestational sac on transvaginal ultrasonography.
We analyzed several patient parameters to determine their association with pregnancy, including age, gravidity, term deliveries, day 3 serum estradiol levels, maximum day 3 serum FSH levels, and accessory infertility diagnoses. In addition, cycle characteristics including stimulation protocol, total gonadotropin dose, day of stimulation, endometrial thickness on day of hCG injection, number of follicles, number of oocytes retrieved, fertilization rate, use of ICSI, use of assisted hatching, number of embryos transferred, and stage and grade of embryos at transfer were examined.

Serum b-FSH levels were determined using a solid phase twosite chemiluminescent immunometric assay, which was run on the Immulite 2500 (Siemens Healthcare Diagnostics, Inc. Tarrytown, NY, USA). The range for testing is up to $170 \mathrm{mlU} /$ $\mathrm{mL}$ and the sensitivity is $0.1 \mathrm{mlU} / \mathrm{mL}$. The Immulite 2500 uses a solid-phase, two-site chemiluminescent immunometric assay (sensitivity: $0.1 \mathrm{IU} / \mathrm{L}$, intra- and interassay coefficients of variation: $4.2 \%$ and $7.9 \%$, respectively).

All statistical analyses were performed using the statistical package for social sciences 11.0 (SPSS Inc., Chicago, IL, USA). Continuous variables were evaluated for normal distribution using the Kolmogorov-Smirnov test. Results are reported as mean value \pm standard deviation (SD). The Student's t-test was used for comparison of nominal data. The Levene's test for equality of variances was applied to the data, and the corresponding t-test and $\mathrm{p}$ values were accepted depending on whether the variances were equal. The Chi-squared test was used to compare noncontinuous variables. Corrections were applied when the cell sizes were less than 5 . For relative risk, CI denotes 95\% confidence interval. Stepwise logistic regression was used to determine the predictors of pregnancy and $\mathrm{CP}$ while controlling for the effect of the other analyzed variables and multiplicity. Statistical significance was accepted as a twosided $\mathrm{p} \leq 0.05$. The university committee for the protection of human research subjects' approval of the study was obtained, and patients were consented for participation.

\section{Results}

All data were normally distributed by the Kolmogorov-Smirnov test.

Forty-nine individuals with serum b-FSH levels meeting the criteria underwent 64 IVF cycles during the study period. Cycles were cancelled in none of the patients. Thirty-two patients underwent regular IVF cycles and 32 underwent intra-cytoplasmic sperm injection (ICSI) cycles. In individuals with the highest FSH level on day 3 of the menstrual cycle being between 10 and $12 \mathrm{IU} / \mathrm{L}$, the $\mathrm{CP}$ rate was $26.5 \%$ per IVF cycle and $35 \%$ per patient. At that time, the overall CP rate per cycle at the Stanford IVF clinic was $27.0 \%$ in women aged 43 years or younger and did not differ from the rate seen in the borderline FSH group. Of the cycles performed at the center during the study period, $59 \%$ were IVF cycles and $41 \%$ were ICSI cycles. Demographics of individuals with borderline b-FSH levels who conceived and failed to conceive with IVF are presented in Table 1. It can be noted that none of these parameters differed between the groups. 
Table 1. Demographics of patients with b-FSH levels between 10.0 to 11.9 who achieved a clinical pregnancy and those who did not conceive

\begin{tabular}{|l|c|c|c|}
\hline & $\begin{array}{c}\text { Clinical } \\
\text { pregnancy } \\
\mathbf{n = 1 7}\end{array}$ & $\begin{array}{c}\text { Not } \\
\text { pregnant } \\
\mathbf{n = 3 2}\end{array}$ & $\mathbf{p}$ \\
\hline Age (years) & $37.3 \pm 4.1$ & $38.7 \pm 3.4$ & 0.24 \\
\hline Gradivity & $1.4 \pm 1.2$ & $1.0 \pm 0.6$ & 0.22 \\
\hline Previous full term pregnancies & $0.5 \pm 0.8$ & $0.3 \pm 0.6$ & 0.36 \\
\hline Highest FSH (mIU/mL) & $10.9 \pm 0.5$ & $10.9 \pm 0.5$ & 0.72 \\
\hline FSH: serum follicle stimulating hormone; n: number of patients \\
\hline
\end{tabular}

Table 2. A comparison of IVF cycle parameters in patients who achieved clinical pregnancy and those who did not

\begin{tabular}{|c|c|c|c|}
\hline & $\begin{array}{c}\text { Clinical } \\
\text { pregnancy } \\
\mathrm{n}=17\end{array}$ & $\begin{array}{c}\text { Not } \\
\text { pregnant } \\
n=47\end{array}$ & $\mathbf{p}$ \\
\hline $\begin{array}{l}\text { Gonadotropin dose } \\
\text { IU/cycle }\end{array}$ & $6203 \pm 1200$ & $6447 \pm 1268$ & 0.52 \\
\hline $\begin{array}{l}\text { Number of days } \\
\text { of stimulation }\end{array}$ & $11.6 \pm 2.1$ & $11.6 \pm 1.4$ & 0.94 \\
\hline $\begin{array}{l}\text { Endometrial echo at last } \\
\text { ultrasonography prior to } \\
\text { retrieval (mm) }\end{array}$ & $10 \pm 2.1$ & $9.7 \pm 2.7$ & 0.62 \\
\hline $\begin{array}{l}\text { Number of follicle with } \\
\geq 15 \text {-mm diameter } \\
\text { on day of hCG }\end{array}$ & $8.6 \pm 3.3$ & $8.0 \pm 2.7$ & 0.49 \\
\hline Number of oocytes retrieved & $7.9 \pm 4.5$ & $7.1 \pm 4.1$ & 0.48 \\
\hline Number of MIIs & $6.9 \pm 5.8$ & $5.3 \pm 4.8$ & 0.27 \\
\hline Percent fertilization & $74 \pm 21$ & $62 \pm 21$ & 0.07 \\
\hline Number of embryos & $5.7 \pm 3.3$ & $4.3 \pm 2.1$ & 0.12 \\
\hline $\begin{array}{l}\text { Number of embryos } \\
\text { transferred }\end{array}$ & $2.6 \pm 1.2$ & $3.2 \pm 1.4$ & 0.12 \\
\hline
\end{tabular}

Patients were more likely to have clinical pregnancy (CP) if they had tubal factor infertility than if they did not (relative risk: $3.7, \mathrm{CI}$ $1.02-14.8, \mathrm{p}=0.05$ ). However, male factor infertility (relative risk: 0.77 , CI 0.34-1.75, $\mathrm{p}=0.51$ ), endometriosis (relative risk: $0.69, \mathrm{CI}$ $0.08-5.76, \mathrm{p}=0.73$ ), and recurrent pregnancy loss (relative risk: 1.50 , Cl 0.15-15.46, $\mathrm{p}=0.11$ ) diagnosis did not decrease $\mathrm{CP}$ rates when compared with individuals without this diagnosis.

$\mathrm{CP}$ rates did not differ based on the stimulation protocol used. If patients had a long Gonadotropin releasing hormone (GnRh)Agonist protocol (relative risk: 0.92, CI 0.10-8.27, $\mathrm{p}=0.94$ ), which constituted $6 \%$ of cycles, a GnRh-antagonist cycle (relative risk: 1.09 , CI $0.712-1.658, \mathrm{p}=0.71$ ), which constituted $61 \%$ of cycles, or a microdose GnRh-agonist flare protocol (relative risk: 0.86 , CI 0.374-1.995, $\mathrm{p}=0.73$ ), which constituted 33 percent of cycles, $\mathrm{CP}$ rates were similar when compared with the average $\mathrm{CP}$ rate of the other two protocols combined.

A comparison of parameters related to IVF stimulation between individuals with the highest serum FSH level of 10-12 IU/L who
Table 3. An evaluation of parameters which predicted pregnancy and clinical pregnancy in all subjects

\begin{tabular}{|c|c|c|}
\hline & Pregnancy & $\begin{array}{c}\text { Clinical } \\
\text { pregnancy }\end{array}$ \\
\hline Age (years) & $0.03^{\mathrm{a}}$ & 0.16 \\
\hline Gravity & $0.04^{\mathrm{a}}$ & 0.14 \\
\hline Full term deliveries & 0.13 & 0.17 \\
\hline Highest FSH (mIU/mL) & 0.76 & 0.72 \\
\hline Serum estradiol $^{\mathrm{b}}$ & 0.78 & 0.70 \\
\hline Gonadotropin dose per cycle & 0.28 & 0.63 \\
\hline Days of stimulation & 0.94 & 0.85 \\
\hline Endometrial thickness & 0.13 & 0.46 \\
\hline $\begin{array}{l}\text { Number of follicle } \geq 15 \mathrm{~mm} \text { diameter } \\
\text { on day of hCG }\end{array}$ & $0.035^{\mathrm{a}}$ & 0.33 \\
\hline Number oocytes retrieved & $0.004^{a}$ & 0.30 \\
\hline$\%$ fertilization & 0.63 & 0.07 \\
\hline Number of embryos & $0.006^{\mathrm{a}}$ & $0.03^{\mathrm{a}}$ \\
\hline Number of embryos transferred & 0.16 & 0.15 \\
\hline \multicolumn{3}{|c|}{$\begin{array}{l}\text { adenotes statistical significance } \\
\text { denotes estradiol associated with the highest FSH levels } \\
\text { Note: stepwise logistic regression was performed which controlled } \\
\text { for intervariable effects and multiplicity } \\
\text { Note: Analysis based on } 64 \text { cycles } \\
\text { FSH: serum follicle stimulating hormone; hCG: human chorionic } \\
\text { gonadotrophin }\end{array}$} \\
\hline
\end{tabular}

conceived with $\mathrm{CP}$ and who failed to conceive is presented in Table 2. None of the parameters presented differed between the two groups.

Having ICSI did not statistically improve the clinical pregnancy rate above standard IVF ( $45 \%$ vs. $28 \%, \mathrm{p}=0.40$ ).

As expected, individuals who had embryo quality that permitted transfer as blastocysts were more likely to have $\mathrm{CP}$ than individuals with day 3 embryo transfers ( $67 \%$ vs. $24 \%$, $\mathrm{p}=0.003$ ). However, embryo quality and quantity in only $14 \%$ of cycles met the criteria to enable embryos to be grown to the blastocyst stage. Based on the criteria at the IVF center, at least 4 good quality embryos were obtained on day 3 after fertilization.

\section{Prediction of Pregnancy and CP among All Subjects}

Stepwise logistic regression was performed to determine if any continuous variable predicted the likelihood of pregnancy and $\mathrm{CP}$ while controlling for the other variables and multiplicity. Factors that were controlled included patient age, number of previous pregnancies, number of full-term pregnancies, previous number of IVF cycles, maximum serum basal serum FSH level, basal serum estradiol level associated with that FSH level, total gonadotropin dose used, and total duration of gonadotropin stimulation and the other IVF cycle outcome parameters listed in the tables (Tables 3-5). The results are shown in Table 3 . As can be noted, subject age ( $37 \pm 0.8$ vs. $39 \pm 0.7$ years), number of pregnancies $(1.5 \pm 0.3$ vs. $0.9 \pm 0.1)$, number of mature follicles on day of hCG triggering ( $9.0 \pm 0.7$ vs. $7.7 \pm 0.4$ ), number 
Table 4. An evaluation of parameters which predict pregnancy and clinical pregnancy in ICSI cycles

\begin{tabular}{|c|c|c|}
\hline & Pregnancy & $\begin{array}{c}\text { Clinical } \\
\text { pregnancy }\end{array}$ \\
\hline Age (years) & 0.70 & 0.62 \\
\hline Gravidity & 0.75 & 0.80 \\
\hline Full term pregnancies & 0.94 & 1.0 \\
\hline IVF Cycle Number & 0.58 & 0.87 \\
\hline Highest FSH (mIU/mL) & 0.17 & 0.18 \\
\hline Serum estradiol $^{\mathrm{b}}$ & 0.23 & 0.52 \\
\hline Gonadotropin dose per cycle & 0.65 & 0.99 \\
\hline Days of stimulation & 0.35 & 0.30 \\
\hline Endometrial thickness & $0.049^{\mathrm{a}}$ & 0.31 \\
\hline $\begin{array}{l}\text { Number of follicle } \geq 15 \mathrm{~mm} \text { diameter } \\
\text { on day of hCG }\end{array}$ & 0.49 & 0.93 \\
\hline Number oocytes retrieved & 0.27 & 0.90 \\
\hline Number of MIIs & 0.53 & 0.085 \\
\hline$\%$ fertilization & 0.86 & 0.15 \\
\hline Number of embryos & 0.31 & 0.21 \\
\hline Number of embryos transferred & 0.94 & 0.62 \\
\hline \multicolumn{3}{|c|}{$\begin{array}{l}\text { adenotes statistical significance } \\
\text { bdenotes estradiol associated with the highest FSH levels } \\
\text { Note: Analysis based on } 32 \text { cycles } \\
\text { FSH: serum follicle stimulating hormone; hCG: human chorionic } \\
\text { gonadotrophin, MIIs: Metaphase II oocytes }\end{array}$} \\
\hline
\end{tabular}

of oocytes retrieved ( $9 \pm 1.0$ vs. $6 \pm 0.5$ ), and number of embryos ( $5.8 \pm 0.7$ vs. $4.1 \pm 0.3$ ) were significant discriminators between individuals who conceived and those who did not. However, only the number of embryos ( $5.7 \pm 0.8$ vs. $4.3 \pm 0.3)$ predicted those who had CP when compared with those who did not. No other variables tested were the predictors of pregnancy or $\mathrm{CP}$ when controlling for the other analyzed factors.

Stepwise logistic regression was used to evaluate only subjects who underwent ICSI. The results are shown in Table 4. As can be noted, endometrial thickness predicted an increase in the pregnancy rate $(p=0.049)$ when controlling for other factors (listed in the paragraph above) and multiplicity. However, endometrial thickness was not a predictor of CP. No other variables tested were the predictors of pregnancy or $\mathrm{CP}$ when controlling for the other analyzed factors among subjects who underwent ICSI.

\section{Prediction of Pregnancy and CP among Non-ICSI Subjects}

Stepwise logistic regression was used to evaluate only subjects who underwent regular IVF. The results are shown in Table 5. Individuals who conceived in comparison with those who did not were younger ( $36.7 \pm 1.5$ vs. $40.7 \pm 0.7$ years), had more previous pregnancies $(2.0 \pm 0.4$ vs. $0.9 \pm 0.2)$, had more mature follicles on the day of hCG triggering $(9.5 \pm 0.8$ vs. $6.9 \pm 0.6)$, had more oocytes retrieved ( $11.2 \pm 1.7$ vs. $5.6 \pm 0.5)$, and had more embryos ( $6.9 \pm 0.9$ vs. $3.8 \pm 0.4)$. In contrast, patients who had $\mathrm{CP}$ had a greater number of previous pregnancies $(2.0 \pm 0.6$ vs. $1.0 \pm 0.2)$, lower maximum serum FSH levels (10.6 \pm 0.2 vs.
Table 5. An evaluation of parameters that predict pregnancy and clinical pregnancy in patients who underwent IVF without ICSI

\begin{tabular}{|c|c|c|}
\hline & Pregnancy & $\begin{array}{c}\text { Clinical } \\
\text { pregnancy }\end{array}$ \\
\hline Age (years) & $0.01^{\mathrm{a}}$ & 0.26 \\
\hline Gravidity & $0.007^{\mathrm{a}}$ & $0.04^{\mathrm{a}}$ \\
\hline Full term pregnancies & 0.08 & 0.06 \\
\hline Highest FSH (mIU/mL) & 0.16 & $0.03^{\mathrm{a}}$ \\
\hline Serum estradiol $^{\mathrm{b}}$ & 0.23 & $0.03^{\mathrm{a}}$ \\
\hline Gonadotropin dose per cycle & 0.17 & 0.59 \\
\hline Days of stimulation & 0.49 & 0.44 \\
\hline Endometrial thickness & 0.48 & 0.89 \\
\hline $\begin{array}{l}\text { Number of follicle } \geq 15 \mathrm{~mm} \text { diameter } \\
\text { on day of hCG }\end{array}$ & $0.016^{\mathrm{a}}$ & 0.29 \\
\hline Number oocytes retrieved & $0.001^{\mathrm{a}}$ & 0.31 \\
\hline$\%$ fertilization & 0.54 & 0.19 \\
\hline Number of embryos & $0.002^{\mathrm{a}}$ & 0.06 \\
\hline Number of embryos transferred & 0.30 & 0.11 \\
\hline \multicolumn{3}{|c|}{$\begin{array}{l}\text { adenotes statistical significance } \\
\text { 'denotes estradiol associated with the highest FSH levels } \\
\text { Note: Analysis based on } 32 \text { cycles } \\
\text { FSH: Serum follicle stimulating hormone, hCG: Human Chorionic } \\
\text { Gonadotrophin }\end{array}$} \\
\hline
\end{tabular}

$11.0 \pm 0.08)$, and higher day 3 estradiol levels ( $61 \pm 19$ vs. $35 \pm 2.4$ ), when compared with individuals who did not achieve $\mathrm{CP}$. The same previously listed factors were controlled.

\section{Discussion}

Women with borderline ovarian reserve have not been well studied in terms of the ART outcome. Due to potential negative effects of elevated b-FSH levels usually greater than at least 12IU/L on the IVF outcome, it may be reasonable to assume that there is an association of a poorer outcome in women with borderline levels of b-FSH compared with those with normal serum day 3 levels.

$\mathrm{CP}$ rates in women who undergo IVF under the age of 35 years have been reported to be anywhere between 30 and $45 \%$ per cycle with mostly cleavage stage transfers (26). During the study period, the CP rate per IVF- embryo transfer (ET) at the Stanford center was $27 \%$. In our patient population with borderline ovarian reserve, overall $\mathrm{CP}$ rates were fairly promising, with $26.5 \%$ per IVF cycle and $35 \%$ per patient. When blastocysts were transferred in a select group of these patients, there was almost a 3-fold increase in CP rates compared with rates in cleavage stage transfers ( $67 \%$ vs. $24 \%, \mathrm{p}=0.003$ ). This was clearly due to a selection bias; highest quality embryos developed into blastocysts, while lower quality embryos were transferred at the cleavage stage. There was no statistical difference in mean ages between the pregnant and nonpregnant groups. Although women with slightly elevated FSH levels may have already showed a decline in their ovarian reserve, 
$\mathrm{CP}$ rates in this study remain reassuring without significant compromise.

A variety of patient parameters were analyzed for an association with pregnancy in an IVF cycle. These data suggested that women with tubal factor infertility were more likely to achieve $\mathrm{CP}$ compared to those with other causes of infertility. It can be speculated that because patients with tubal factor infertility are unable to conceive without IVF, these patients differ from those with other infertility diagnoses, who have better prognosis and conceive without assistance and do not require treatment.

When many IVF cycle characteristics were examined in these women with borderline ovarian reserve, several interesting findings were noted. For example, stimulation protocols did not affect the likelihood of achieving $\mathrm{CP}$ in a patient. Although long protocols are usually performed in women with better prognoses, likely with lower FSH levels, we found no difference in cycle outcomes in these patients when comparing with those treated with microdose flare agonist and antagonist protocols. This may be due to the very low number of long protocols utilized in this group of women with relatively high b-FSH levels (4 cycles of 64); another reason may be that long protocols may result in similar or better stimulations than the microdose flare or antagonist protocols.

When analyzing the effects of the method of oocyte insemination on the cycle outcome in women with borderline normal b-FSH levels, having ICSI did not improve the $\mathrm{CP}$ rate above standard IVF ( $45 \%$ vs. $28 \%, p=n s$ ). This trend of $45 \%$ of ICSI cycles achieving pregnancy while only $28 \%$ of standard IVF cycles did so may have been significant with a greater sample size. This nonstatistically significant trend of increased pregnancy rates with ICSI as opposed to regular IVF may be due to a reduced capability of sperm penetration of oocytes derived from women with higher b-FSH levels. De Mola et al. (27) found a significant positive correlation between b-FSH levels and zona pellucida thickness. In patients who underwent ICSI, the only parameter that predicted pregnancy was endometrial thickness. This finding coincides with the belief that the endometrium plays a pivotal role in the success of IVF. Age was not a factor that predicted outcomes of IVF cycles in women with borderline b-FSH levels who underwent ICSI.

The results differ in patients whose oocytes were not inseminated with ICSI. Age, gravidity, number of mature follicles and oocytes retrieved, and number of embryos all predicted pregnancy, while only gravidity continued to predict CP. Highest b-FSH levels and correlating estradiol levels also predicted CP. On the other hand, assisted hatching was associated with a lower $\mathrm{CP}$ rate when compared with those who did not undergo this procedure. As mentioned previously, this is likely due to the fact that patients who underwent assisted hatching were older and were less likely to have had a blastocyst transfer; therefore, the outcome was skewed.

Strengths of this study include that it was performed prospectively, and it is one of the few in the literature that evaluated this cohort. Weaknesses of the study include the smaller population size. The small sample size may have affected the power to detect some significant predictors of pregnancy. However, it should be noted that several significant predictors were detected with statistical modeling, even at this small sample size, stressing the clinical significance of these predictors. Antimullerian hormone levels were measured at the discretion of the physician. Because patients clearly had borderline ovarian reserve and were offered IVF, it was not measured in most cases.

In conclusion to our knowledge, this is the first article addressing outcome predictors in infertility patients with b-FSH levels between 10.0 and $11.9 \mathrm{IU} / \mathrm{L}$ who were treated with IVF. We have shown that pregnancy rates per cycle and per patient were not significantly different from those of similar-age patients with b-FSH levels below $10 \mathrm{IU} / \mathrm{L}$.

Ethics Committee Approval: Ethics committee approval was received for this study from the ethics committee of Stanford University Medical Center.

Informed Consent: Written informed consent was obtained from patients who participated in this study.

Peer-review: Externally peer-reviewed.

Author contributions: Concept - S.J., M.D.; Design - S.J., M.D.; Data Collection\&/or Processing - S.J., M.D.; Analysis\&/or Interpretation - D.L., S.J., M.D.; Literature Search - D.L.; Writing - D.L., S.J., M.D.

Acknowledgements: Funding: NICHD through NIH grant 5K12HD01249

Conflict of Interest: No conflict of interest was declared by the authors. Financial Disclosure: None.

\section{References}

1. Kligman I, Rosenwaks Z. Differentiating clinical profiles: predicting good responders, poor responders, and hyperresponders. Fertil Steril 2001; 76: 1185-90. [CrossRef]

2. Bancsi LF, Broekmans FJ, Eijkemans MJ, de Jong FH, Habbema JD, te Velde ER. Predictors of poor ovarian response in in vitro fertilization: a prospective study comparing basal markers of ovarian reserve. Fertil Steril 2002; 77: 328-36. [CrossRef]

3. Loumaye E, Billion JM, Mine JM, Psalti I, Pensis M, Thomas K. Prediction of individual response to controlled ovarian hyperstimulation by means of a clomiphene citrate challenge test. Fertil Steril 1990; 53: 295-301.

4. Padilla SL, Bayati J, Garcia JE. Prognostic value of the early serum estradiol response to leuprolide acetate in in vitro fertilization. Fertil Steril 1990; 53: 288-94.

5. Seifer DB, Lambert-Messerlian G, Hogan JW, Gardiner AC, Blazar AS, Berk CA. Day 3 serum inhibin-B is predictive of assisted reproductive technologies outcome. Fertil Steril 1997; 67: 110-4. [CrossRef]

6. Chang MY, Chiang $\mathrm{CH}$, Hsieh TT, Soong YK, Hsu KH. Use of the antral follicle count to predict the outcome of assisted reproductive technologies. Fertil Steril 1998; 69: 505-10. [CrossRef]

7. Syrop CH, Willhoite A, Van Voorhis BJ. Ovarian volume: a novel outcome predictor for assisted reproduction. Fertil Steril 1995; 64: 1167-71.

8. Fanchin R, de Ziegler D, Olivennes F, Taieb J, Dzik A, Frydman R. Exogenous follicle stimulating hormone ovarian reserve test (EFORT): a simple and reliable screening test for detecting 'poor responders' in in-vitro fertilization. Hum. Reprod (Oxford, England) 1994; 9: 1607-11.

9. Navot D, Rosenwaks Z, Margalioth EJ. Prognostic assessment of female fecundity. Lancet 1987; 2: 645-7. [CrossRef]

10. Bancsi LF, Broekmans FJ, Mol BW, Habbema JD, te Velde ER. Performance of basal follicle-stimulating hormone in the predic- 
tion of poor ovarian response and failure to become pregnant after in vitro fertilization: a meta-analysis. Fertil Steril 2003; 79: 1091-100. [CrossRef]

11. Muasher SJ, Oehninger S, Simonetti S, Matta J, Ellis LM, Liu HC, Jones GS. The value of basal and/or stimulated serum gonadotropin levels in prediction of stimulation response and in vitro fertilization outcome. Fertil Steril 1988; 50: 298-307.

12. Bancsi LF, Huijs AM, den Ouden CT, Broekmans FJ, Looman CW, Blankenstein MA, te Velde ER. Basal follicle-stimulating hormone levels are of limited value in predicting ongoing pregnancy rates after in vitro fertilization. Fertil Steril 2000; 73: 552-7. [CrossRef]

13. van Rooij IAJ, de Jong E, Broekmans FJM, Looman CWN, Habbema JDF, te Velde ER. High follicle-stimulating hormone levels should not necessarily lead to the exclusion of subfertile patients from treatment. Fertil Steril 2004; 81: 1478-85. [CrossRef]

14. Fasouliotis SJ, Simon A, Laufer N. Evaluation and treatment of low responders in assisted reproductive technology: a challenge to meet. J Assist Reprod Genet 2000; 17: 357-73. [CrossRef]

15. Scott RT, Toner JP, Muasher SJ, Oehninger S, Robinson S, Rosenwaks Z. Follicle-stimulating hormone levels on cycle day 3 are predictive of in vitro fertilization outcome. Fertil Steril 1989; 51: 651-4.

16. Toner JP, Philput CB, Jones GS, Muasher SJ. Basal follicle-stimulating hormone level is a better predictor of in vitro fertilization performance than age. Fertil Steril 1991; 55: 784-91.

17. Weghofer A, Margreiter M, Fauster Y, Schaetz T, Brandstetter A, Boehm D, Feichtinger W. Age-specific FSH levels as a tool for appropriate patient counselling in assisted reproduction. Hum Reprod 2005; 20: 2448-52. [CrossRef]

18. Wolff EF, Taylor HS. Value of the day 3 follicle-stimulating hormone measurement. Fertil Steril 2004; 81: 1486-8; discussion 496-7. [CrossRef]
19. Toner JP, Flood JT. Fertility after the age of 40. Obstet Gynecol Clin North Am 1993; 20: 261-72.

20. Kojima R, Nakagawa K, Nakashima A, Horikawa T, Ohgi S, Saito H. Elevated basal FSH levels, if it is under $15 \mathrm{IU} / \mathrm{L}$, will not reflect poor ART outcomes. J Assist Reprod Genet 2008; 25: 73-7. [CrossRef]

21. Bongaarts $\mathrm{J}$. The fertility impact of changes in the timing of childbearing in the developing world. Popul Stud (Camb) 1999; 53: 27789. [CrossRef]

22. Ford D, Nault F. Changing fertility patterns, 1974 to 1994 . Health reports / Statistics Canada, Canadian Centre for Health Information = Rapports sur la sante / Statistique Canada, Centre canadien d'information sur la sante 1996; 8: 39-46(Eng); 3-51(Fre).

23. Heck KE, Schoendorf KC, Ventura SJ, Kiely JL. Delayed childbearing by education level in the United States, 1969-1994. Matern Child Health J 1997; 1: 81-8. [CrossRef]

24. MacNaughton J, Banah M, McCloud P, Hee J, Burger H. Age related changes in follicle stimulating hormone, luteinizing hormone, oestradiol and immunoreactive inhibin in women of reproductive age. Clin Endocrinol (Oxf) 1992; 36: 339-45. [CrossRef]

25. van der Steeg JW, Steures P, Eijkemans MJ, Habbema JD, Hompes PG, Broekmans FJ, et al. Predictive value and clinical impact of Basal follicle-stimulating hormone in subfertile, ovulatory women. J Clin Endocrinol Metab 2007; 92: 2163-8. [CrossRef]

26. Assisted reproductive technology in the United States: 2001 results generated from the American Society for Reproductive Medicine/ Society for Assisted Reproductive Technology registry. Fertil Steril 2007; 87: 1253-66. [CrossRef]

27. Loret De Mola JR, Garside WT, Bucci J, Tureck RW, Heyner S. Analysis of the human zona pellucida during culture: correlation with diagnosis and the preovulatory hormonal environment. J Assist Reprod Genet 1997; 14: 332-6. [CrossRef] 